\title{
A IMPORTÂNCIA DA INCUBADORA DE EMPRESAS NO DESENVOLVIMENTO DO EMPREENDEDORISMO
}

\author{
THE IMPORTANCE OF BUSINESS INCUBATOR IN ENTREPRENEURSHIP \\ DEVELOPMENT
}

\section{Thiago Flávio de Souza}

Mestre em Administração

Docente do Curso de Administração - Facer Faculdade de Ceres, Ceres-GO

Docente do Curso de Administração - Facer Faculdade de Jaraguá, Jaraguá-GO

flaviothiago@gmail.com

\section{Resumo}

O tema empreendedorismo e incubadoras de empresas têm sido motivo de diversas discussões e estudos, que visam compreender este cenário tão importante para o desenvolvimento de novos empreendimentos. O objetivo deste artigo consiste em identificar por meio da literatura a importância das incubadoras para o desenvolvimento do empreendedorismo. Na revisão da literatura optou-se por conceituar as incubadoras de empresas, seus objetivos, tipos e sua trajetória vivificada na história, possibilitando caracterizar esse setor e entender ainda mais suas particularidades. O método adotado para o presente estudo compreende-se do tipo descritivo com base no material bibliográfico estudado. Como resultado observou-se a importância das incubadoras, sendo esse fato justificado nas consultorias proporcionadas e no apoio administrativo, estrutural e financeiro, oferecido aos empreendedores permitindo o reconhecimento do sucesso de seus empreendimentos.

Palavras-chave: Incubadora, Empreendedorismo, Negócios.

\begin{abstract}
The theme entrepreneurship and business incubators have been the subject of several discussions and studies aimed at understanding this scenario as important to the development of new projects. The purpose of this article is to identify through literature the importance of incubators for the development of entrepreneurship. In the literature review we chose to conceptualize business incubators, objectives, types and quickened his career in history, allowing characterize this sector and further understand its peculiarities. The method adopted for this study comprises up descriptive based on bibliographic material studied. As a result there was the importance of the incubators, and this fact is justified in provided consulting and administrative, structural and financial support offered to entrepreneurs allowing the recognition of the success of your endeavors.
\end{abstract}

Keywords: Incubator, Entrepreneurship, Business. 
A criação do próprio negócio na maioria das vezes se configura como a materialização de um sonho ou ideal, mas o que preocupa é que diversas pessoas dão início ao empreendimento sem nenhum tipo de preparo e informação, outros ainda atuam de maneira informal, prejudicando a manutenção e a sustentabilidade da empresa.

De acordo com a pesquisa de monitoramento da sobrevivência e mortalidades de empresas realizadas pelo SEBRAE (2014), 27\% das empresas paulistanas fecham em seu $1^{\circ}$ ano de atividade. Esse índice foi o menor obtido em 10 anos de monitoramento por parte do SEBRAE-SP.

Diante do crescente número de novos empreendimentos, aliado a alta taxa de mortalidade das empresas, as características empreendedoras ganharam grande importância garantindo um aumento significativo na busca pelo aperfeiçoamento e conhecimento das atividades empresariais.

Segundo Dornelas (2000, p. 17), “o momento é propício para uma análise apurada das relações existentes entre incubadoras e empreendedorismo, haja vista o fato de o Brasil estar sendo relacionado entre os países que têm a maior atividade empreendedora do mundo, com índices comparáveis inclusive aos dos Estados Unidos, pais referência no tema”.

O papel desenvolvido pelas incubadoras, tanto no incentivo a geração de empresas competitivas como na formação de empreendedores, motivou a realização deste estudo. Esta pesquisa objetivou estudar a importância da incubadora no desenvolvimento do empreendedorismo. O trabalho conseguiu resultados importantes da relação entre incubadora e empreendedorismo, demonstrando a eficiência das ações desempenhadas na criação de empresas de sucesso.

\section{Incubadoras e seus conceitos}

Existem diversas definições na literatura sobre o conceito de incubadoras de empresas, no entanto com a variedade existente sua definição se torna difícil, o que foi evidenciado por Vedovello (2000, p. 280) onde cita que: "não há uma definição única que possa ser aplicada a todos os parques de tecnologia e incubadoras de empresas, devido ao fato de esses mecanismos apresentarem uma diversidade e uma heterogeneidade muito grandes em relação aos seus modelos". Mesmo diante desse cenário, a seguir destacam-se algumas definições conforme o Quadro 1. 
Quadro 1 - Conceito de Incubadora

\begin{tabular}{|c|c|}
\hline $\begin{array}{lll}\text { Raupp e Beuren } \\
(2009) & & \end{array}$ & $\begin{array}{l}\text { Compreendem de um ambiente propício para o desenvolvimento de novos } \\
\text { negócios que facilita o acesso ao conhecimento e a entidades fornecedoras } \\
\text { financiamentos. }\end{array}$ \\
\hline $\begin{array}{l}\text { Bergek e Norrman } \\
\text { (2008) }\end{array}$ & $\begin{array}{l}\text { Abrangem organizações que possuem uma localização conjunta e oferecem } \\
\text { apoio, por meio de serviços, às empresas que participam da rede durante a } \\
\text { fase inicial do empreendimento. }\end{array}$ \\
\hline Dornelas (2007) & $\begin{array}{l}\text { São mecanismos mantidos por entidades governamentais, universidades, } \\
\text { grupos comunitários entre outros que utilizam um ambiente no qual são } \\
\text { oferecidas facilidades para o surgimento e o crescimento de novos } \\
\text { empreendimentos. }\end{array}$ \\
\hline $\begin{array}{l}\text { Luzzardi; Oliveira; } \\
\text { Duhá (2006) }\end{array}$ & $\begin{array}{l}\text { Organismo capaz de auxiliar as novas empresas, a partir de formação de } \\
\text { parcerias estratégicas, capacitação para inovação; sendo um importante } \\
\text { mecanismo de geração de empregos e de desenvolvimento regional e } \\
\text { nacional. }\end{array}$ \\
\hline $\begin{array}{l}\text { Grimaldi e Grandi } \\
\text { (2005) }\end{array}$ & $\begin{array}{l}\text { É um meio eficaz de ligação entre tecnologia, capital e know-how em busca } \\
\text { de alavancar o empreendedorismo, motivar a criação de novas empresas, e } \\
\text { acelerar a exploração da tecnologia, fornecendo um espaço flexível e a } \\
\text { partilha de equipamentos e serviços administrativos. }\end{array}$ \\
\hline $\begin{array}{l}\text { Quadros (2004, p. } \\
\text { 26) }\end{array}$ & $\begin{array}{l}\text { "composta por um ambiente flexível e encorajador onde é oferecida uma série } \\
\text { de facilidades para o surgimento e crescimento de novos empreendimentos a } \\
\text { um custo bem menor do que no mercado, na medida em que esses custos são } \\
\text { rateados e muitas vezes subsidiados". }\end{array}$ \\
\hline $\begin{array}{l}\text { Bhabra-Remedios e } \\
\text { Cornelius (2003) }\end{array}$ & $\begin{array}{l}\text { São redes de apoio a inovação tecnológica, formada por um processo } \\
\text { dinâmico onde empresas jovens são alimentadas para sobreviverem durante } \\
\text { os períodos de incerteza, principalmente durante a fase inicial do negócio. }\end{array}$ \\
\hline Uggioni (2002) & $\begin{array}{l}\text { Uma instalação planejada para apoiar o desenvolvimento de empresas } \\
\text { inovadoras, provendo diversos serviços e apoio para o início de } \\
\text { empreendimentos de alta tecnologia nascentes ou negócios tradicionais. }\end{array}$ \\
\hline
\end{tabular}

Fonte: Elaborado pelo autor.

\section{$3 \quad$ Objetivos das incubadoras}

$\mathrm{Na}$ busca de identificar os objetivos que as incubadoras de empresas possuem, é possível encontrar diversas opiniões que, no entanto definem da mesma forma, relacionando 
diretamente as suas ações de criar e dar apoio a novos empreendimentos desenvolvendo grande importância social nas comunidades envolvidas.

De acordo com Dornelas (2008), o principal objetivo de uma incubadora está no desenvolvimento de empresas de sucesso, financeiramente viáveis e altamente competitivas em seu negócio, sendo necessário estar em constante desenvolvimento até mesmo após deixar à incubadora.

Para o Instituto Nacional de Telecomunicações - INATEL (2014), o objetivo geral das incubadoras é acelerar o processo de criação de micro e pequenas empresas aumentando suas chances de sobrevivência e os objetivos específicos devem estar alinhados com as expectativas regionais e locais de cada empresa incubada. Quadro 2.

Quadro 2 - Objetivos específicos das incubadoras de empresas

\begin{tabular}{|l|}
\hline 1. Reforçar o espírito empreendedor; \\
\hline 2. Capacitar os empresários; \\
\hline 3. Estimular a associação entre as universidades e as empresas; \\
\hline 4. Estimular a parceria entre as empresas; \\
\hline 5. Apoiar a geração de empregos e de renda; \\
\hline 6. Apoiar a introdução de novos produtos, processos e serviços no mercado; \\
\hline 7. Facilitar o acesso a tecnologias; \\
\hline 8. Apoiar projetos de revitalização de empresas; \\
\hline 9. Consolidar micro e pequenas empresas que apresentem potencial de crescimento; \\
\hline 10. Reduzir a taxa de mortalidade de novas micro e pequenas empresas. \\
\hline
\end{tabular}

Fonte: Elaborado pelo autor, baseado em INATEL (2014)

O objetivo base de uma incubadora está em reduzir a taxa de mortalidade das MPE's, por meio do apoio estratégico durante os primeiros anos do empreendimento. Sendo sua finalidade maior, a preparação das novas empresas para que elas possam se manter no mercado competitivamente. (CHAVES e SILVA 2004); (QUADROS 2004). Complementando Luzzardi; Oliveira; Duhá (2006) destacam que os empreendedores utilizam as incubadoras como catalisador das necessidades para o desenvolvimento de suas capacidades, promovendo os objetivos das incubadoras na minimização dos altos índices de fracasso e no incentivo para o nascimento de novos negócios. 
Vedovello (2000) relata que em um sentido mais amplo, o principal objetivo de uma incubadora de empresas está em facilitar e permitir o desenvolvimento econômico por meio da melhoria da base empresarial e na criação de novos empreendedores.

Segundo Uggioni (2002) as incubadoras possuem como objetivo nos processos de incubação: a redução da taxa de mortalidade das empresas; geração de inovação tecnológica; geração de novos postos de trabalho; transferência de tecnologia entre universidades, centros de pesquisa tecnológica e novos empreendimentos; propiciar taxas de crescimento acelerado entre os novos empreendimentos incubados e influenciar a cultura tecnológica da região onde se encontra instalada.

\section{$4 \quad$ Tipos de Incubadoras}

De modo geral, existem dois tipos básicos de incubadoras, onde Moreira (2002) as denomina de públicas e privadas. Dessa forma o autor caracteriza as incubadoras públicas com as que possuem por objetivos criar oportunidades para a sociedade onde a maioria é apoiada pelo governo, não têm intenção de lucro, sua origem está associada a fundações e instituições que as gerenciam. Já as incubadoras privadas têm a participação de investidores financeiros e institucionais ou de Incubadoras de Empresas, geradas a partir de empresas de grande porte que desenvolvem este tipo de programa objetivando a criação de novas tecnologias e negócios. Nesse caso as incubadoras possuem fins lucrativos e seu processo de admissão é mais restrito que as públicas.

De acordo com Inovates (2014) as incubadoras são consideradas como centros que estimulam a criação de empreendimentos, sendo classificados em:

a. Incubadora de empresas de base tecnológica: Abriga empreendimentos na área de informática, biotecnologia, química fina, mecânica de precisão e novos materiais.

b. Incubadora de empresas de setores tradicionais: Organização que abriga empreendimentos ligados aos setores da economia que detêm tecnologias largamente difundidas e que queiram agregar valor aos seus produtos, processos ou serviços, por meio de incremento em seu nível tecnológico.

c. Incubadora mista: Organização que abriga ao mesmo tempo empresas de base tecnológica e de setores tradicionais.

d. Incubadora setorial: Organização que abriga empreendimentos de apenas um setor da economia. 
e. Incubadora cultural: Apóia empreendimentos voltados para a área da cultura, como, por exemplo, música, escultura, fotografia, cinema, eventos, entre outras do mesmo grupo de atuação.

f. Incubadora social: São incubadoras que apóiam empreendimentos oriundos de projetos sociais, ligados aos setores tradicionais, cujo conhecimento é de domínio público, e que atendam à demanda de emprego e renda e de melhoria da qualidade de vida da comunidade.

g. Incubadora agroindustrial: Organização que abriga empreendimentos de produtos e serviços agropecuários, com vistas a facilitar o processo empresarial e de inovação tecnológica.

h. Incubadora de cooperativa: Incubadora que apóia cooperativas em processo de formação e/ou consolidação instaladas dentro ou fora do município com o objetivo de criação de trabalho e renda.

\section{$5 \quad$ Histórico das incubadoras no Mundo}

De acordo com Dias e Carvalho (2002) as primeiras atividades conhecidas como de incubação de empresas nasceram nos Estados Unidos, da difusão de três diferentes iniciativas - de condomínios de empresas, o de programas de empreendedorismo, e o de investimentos em novas empresas de tecnologia.

Exatamente em 1959 no estado de Nova Iorque (EUA) surgiu a primeira incubadora, quando uma das fábricas da Massey Ferguson fechou, deixando um significativo número de residentes nova-iorquinos desempregados. Joseph Mancuso, comprador das instalações da fábrica, resolveu sublocar o espaço para pequenas empresas iniciantes, que compartilhavam equipamentos e serviços (ANPROTEC, 2014).

Dentre as primeiras empresas que se instalou no "condomínio" de Mancuso estava um aviário, que acabou conferindo ao prédio o apelido de incubadora. Posteriormente, por meio da iniciativa da National Science Foundation dos Estados Unidos, as maiores universidades do País iniciaram programas de empreendedorismo e de geração de inovação em centros de pesquisa com a participação de alunos e professores (DIAS; CARVALHO, 2002).

Estes programas tinham por objetivo maior, promover a transferência da tecnologia desenvolvida na universidade às empresas e a criação de novas empresas intensivas em tecnologia, sobretudo do setor eletrônico. Com o resultado obtido nessa experiência houve a 
reprodução de iniciativas semelhantes em outras localidades, dentro e fora dos Estados Unidos (MCT, 2000, p. 10).

Atualmente, os programas de incubadoras de empresas agrupam em suas estruturas os três modelos originais desenvolvidos há cinco décadas. Assim, atuam na formação de empreendimentos e empreendedores, por meio dos serviços oferecidos e de capital humano com o apoio de alguns investidores amparados por centros de pesquisas, onde em sua maioria são constituídos por universidades e programas tecnológicos.

\subsection{Histórico das incubadoras no Brasil}

Conforme relata Moreira (2002) no Brasil, o surgimento das incubadoras ocorreu em meados da década de 80, a partir de iniciativas junto a universidades e centros de pesquisa, financiadas em sua maioria pelo poder público. Baseadas em um modelo de inovação semelhante ao dos Estados Unidos, as incubadoras e centros de pesquisa vêm tentando se desenvolver em um ambiente não tão hostil como o de seu país de origem, mas é evidente que este movimento vem evoluindo e se fortalecendo ano a ano no Brasil.

A primeira incubadora no Brasil de acordo com o MTC (2000) foi instalada em 1985, na cidade de São Carlos, com o apoio do CNPq, onde posteriormente foram inauguradas as unidades de Florianópolis, Curitiba, Campina Grande e Distrito Federal.

Com base no gráfico a seguir publicado pela ANPROTEC (2006) em sua pesquisa sobre a evolução do movimento brasileiro de incubadoras iniciada desde o ano de 1988, é possível identificar como essa atividade ganhou força e representatividade a partir da criação de sua entidade específica em 1987, e dos critérios e políticas para atuação das incubadoras associadas.

Gráfico 01 - Número de incubadoras em operação 2006

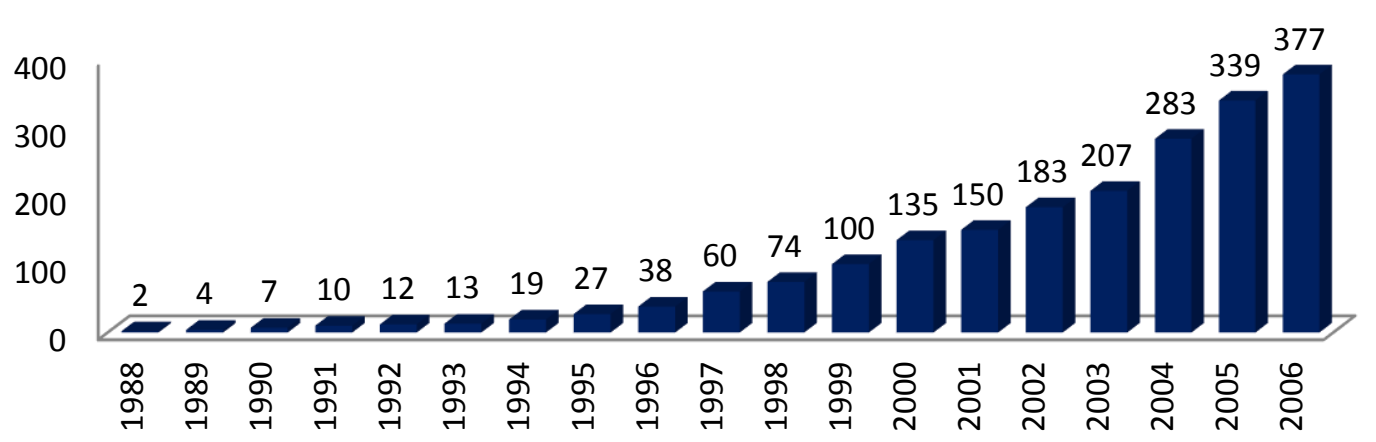

Fonte: Elaborado pelos autor, baseado em ANPROTEC (2006) 
As empresas se integram as incubadoras na busca de benefícios para garantir o sucesso do empreendimento. Algumas vantagens que as empresas encontram nas incubadoras são destacadas por Quadros (2004), sendo:

a. infraestrutura: espaço físico (individual ou coletivo), laboratórios, auditório, biblioteca, salas de reunião, recepção, copa cozinha, estacionamento;

b. facilidade ao acesso de serviços: telefonia, água, luz, telefone, internet, recepcionista, segurança, correios e etc.;

c. assessoramento do negócio: gerencial, contábil, jurídico, apuração e controle de custo, gestão financeira, comercialização, exportação e para o desenvolvimento do negócio;

d. qualificação: treinamento, cursos, acesso a periódicos como jornais, revistas e outras publicações;

e. rede de relacionamentos: manutenção de contatos de alto nível com entidades governamentais e investidores, participação em eventos de divulgação das empresas e workshops.

De certo, tais vantagens tiveram grande contribuição para o aumento do número de incubadoras de empresas no decorrer da história dessas entidades no Brasil, demonstrando a necessidade de apoio que os novos empreendedores possuem para a gestão eficaz e correta dos negócios.

\section{6}

\section{Metodologia}

Diante do referencial teórico encontrado sobre incubadoras de empresas e do desenvolvimento do empreendedorismo de modo geral, a revisão bibliográfica teve a intenção de levantar pontos que atendessem ao objetivo da pesquisa. Toda a abordagem metodológica foi estruturada com o propósito de identificar a importância da incubadora no desenvolvimento do empreendedorismo, por meio da revisão bibliográfica proposta.

Segundo Gil (1999), as pesquisas descritivas têm como finalidade principal a descrição das características de determinada população ou fenômeno, ou o estabelecimento de relações entre variáveis. São inúmeros os estudos que podem ser classificados sob este título e uma de suas características mais significativas aparece na utilização de técnicas padronizadas de coleta de dados.

Vergara (2000, p. 47) argumenta que a pesquisa descritiva expõe as características de determinada população ou fenômeno, estabelece correlações entre variáveis e define sua 
natureza. "Não têm o compromisso de explicar os fenômenos que descreve, embora sirva de base para tal explicação".

Complementando, de acordo com Aaker, Kumar \& Day (2004), a pesquisa descritiva, normalmente, usa dados dos levantamentos e caracteriza-se por hipóteses especulativas que não especificam relações de causalidade.

\section{$7 \quad$ Resultados e Discussão}

Por meio do estudo, identificaram-se importantes aspectos que intensificam a condição de sucesso das empresas que buscam o apoio das incubadoras de empresas. A incubadora representa de fato grande destaque no desenvolvimento do empreendedorismo, em virtude do trabalho focado em favor de melhorias a empreendimentos sem base de negócios e com pouco ou nenhum suporte administrativo.

As incubadoras de empresas representam suma importância para o desenvolvimento do empreendedorismo, a justificativa para tal afirmação, norteia-se no crescimento sustentável dos negócios incubados e também daqueles imersos no mercado, ou seja, que amadureceram suas estratégias e negócios por meio das incubadoras.

Diversos benefícios podem ser encontrados em uma incubadora, porém o principal deles está na consultoria, onde são desenvolvidas todas as áreas do conhecimento. Isso acontece, pois os empreendedores podem não possuir formação especifica na área administrativa, dessa forma a incubadora desempenha papel fundamental no gerenciamento dos negócios incubados, sendo essa uma das características evidenciada por Maehler (et al., 2006), em um estudo realizado sobre a visão que os empreendedores de base tecnológica possuíam das incubadoras na qual se encontravam incubados.

Uma das grandes dificuldades encontradas para o não desenvolvimento de novos negócios está na falta de capital para o investimento inicial, que de acordo com Vedovello (2000), pode representar uma barreira para o crescimento desse setor. A motivação para empreender pode estar vinculada a razão do baixo investimento necessário para abertura do empreendimento, o que por sua vez favorece a condição de diversos Micros Empreendedores Individuais (MEI), como sendo uma alternativa para atingir ganhos financeiros ou até mesmo a realização profissional.

A busca pela incubadora é caracterizada em dois aspectos, sendo tanto no suporte administrativo como também em melhores instalações. Evidentemente que essa mistura proporciona uma condição fortemente favorável, pois ao passo que um empreendimento 
encontra-se incubado maiores facilidades no acesso aos consultores e gestores terão os empreendedores, permitindo assessoria nas estratégias e tomadas de decisão dos negócios durante a sua fase inicial.

Portanto, a busca por melhores instalações em incubadoras de empresas, onde diferentes benefícios relativos a essa parceria são visíveis pela revisão realizada, mostra-se como sendo boa parte destes em virtude da diversidade de serviços que a mesma oferece (telefone, fax, copiadoras, ferramentas) e ainda nos menores custos proveniente da parceria existente. Complementando conforme Baêta; Borges e Tremblay (2006) as incubadoras de empresas passaram a constituir um reduto de idéias e oportunidades especialmente para as micro e pequenas empresas, fornecendo aos empreendedores, suporte administrativo, financeiro e de estrutura.

\section{Conclusão}

Os ganhos e incentivos encontrados nas incubadoras sem dúvida alguma permitem que o tino empreendedor seja aprimorado, valorizando as ideias e transformando-as em negócios, modificando o cenário socioeconômico regional. Embora existam limitações ao estudo, seus resultados demonstram a importância dessa atividade para o estímulo da capacidade empreendedora e consequentemente a eficácia das empresas nela desenvolvida.

A partir da análise dos objetivos das incubadoras tratados na revisão da literatura, pode-se dizer que sua aplicabilidade vem de encontro com os interesses e anseios dos empreendimentos que nela se instalam, sendo justificado por meio das vantagens e no apoio identificado.

Convém pontuar que apesar das limitações encontradas na pesquisa, os objetivos do estudo foram alcançados, permitindo a compreensão da importância das incubadoras de empresas no desenvolvimento do empreendedorismo, e a existência do apoio dedicado aos negócios com base nos índices obtidos pelas agências, comprometidas com a sustentabilidade dos empreendimentos. A partir deste estudo, nota-se que o tema não se esgota, permitindo que novos trabalhos busquem nas incubadoras diversas experiências científicas.

\section{Referências}

AAKER, D. A.; KUMAR, V.; DAY, G. S. Pesquisa de marketing. São Paulo: Atlas, 2004. 
ANPROTEC. Panorama ANPROTEC 2000. Publicado em 2000. Disponível em: < http://www.anprotec.org.br/ArquivosDin/Panorama2000_pdf_29.pdf >. Acesso em: 29 ago. 2014. 11:43:12.

ANPROTEC. Pesquisa 2006. Publicado em 2006. Disponível em: < http://www.anprotec.org.br/ArquivosDin/Graficos_Evolucao_2006_Locus_pdf_59.pdf >. Acesso em: 31 ago. 2014. 22:22:17.

ANPROTEC. Histórico do setor de incubação de empresas no Brasil e no mundo. Disponível em: http://www.anprotec.org.br/publicacaoconhecas2.php?idpublicacao=80. Acesso em: 04 out. 2014. 14:24:29.

BAÊTA, A. M. C.; BORGES, C. V.; TREMBLAY, D. G. Empreendedorismo nas Incubadoras: reflexões sobre tendências atuais. Comportamento Organizacional e Gestão, v. 12, n. 1, p. 7-18, 2006.

BHABRA-REMEDIOS, R. K.; CORNELIUS, B. Cracks in the Egg: improving performance measures in business incubator research. Annual Conference of Small Enterprise Association of Australia and New Zealand, n. 16, 2003.

BERGEK, A.; NORRMAN, C. Incubator best practice: a framework. Technovation: Elsevier. n. 28, p. 20-28, 2008.

CHAVES, C. M. L.; SILVA, M. C. M. As incubadoras de empresas como parceiras dos empreendedores: um estudo sobre as incubadoras situadas no nordeste. In: Anais ENANPAD, 2004.

DIAS, C.; CARVALHO, L.F. Panorama mundial das incubadoras. In: ARANHA, J.A. Modelo de gestão para incubadoras de empresas: implementação do modelo. Rio de Janeiro: Rede de Incubadoras do Rio de Janeiro, 2002.

DORNELAS, J. C. A. Planejando Incubadoras de Empresas. Rio de Janeiro: Campos, 2007.

DORNELAS, J. C. A. Empreendedorismo: transformando idéias em negócios. 3. ed. Rio de Janeiro: Elsevier, 2008. 222 p.

DORNELAS, J. C. A. Planejando Incubadoras de Empresas: como desenvolver um plano de negócios para incubadoras. Rio de Janeiro: Campos, 2002. 134 p.

GIL, A. C. Métodos e técnicas de pesquisa social. 5. ed. São Paulo: Atlas, 1999.

GRIMALDI, R.; GRANDI, A. Business incubators and new venture creation: na assessment of incubating models. Technovation: Elsevier. n. 25, p. 111-121, 2005.

INATEL. Instituto Nacional de Telecomunicações. Disponível em: < http://incubadora.inatel.br/empresas/incubadora/conceito-de-incubadoras-deempresas.html > Acesso em: 30 ago. 2014. 00:31:47.

INOVATES. Tipos de Incubadoras. Disponível em: < http://www.inovates.com.br/incubacao/tiposIncubadoras.php > Acesso em: 31 ago. 2014. 00:49:26.

LUZZARDI, C. P.; OLIVEIRA, M.; DUHÁ, A. H. Desenvolvimento de capacidades e competências: relação entre incubadora e empresas incubadas. In: Anais XXIV Simpósio de Gestão da Inovação Tecnológica, 2006.

MAEHLER, A. E.; COSTA, S.; SCHUCH JUNIOR, V. F.; CASSANEGO JUNIOR, P. V. IPP - Incubadoras, Pólos e Parques. In: Anais XXIV Simpósio de Gestão da Inovação Tecnológica, 2006. 
MCT. Manual para a implantação de incubadoras de empresas. Publicado em 2000. Disponível em: < http://www.mct.gov.br/Temas/Desenv/Manual-Incubadoras.pdf >. Acesso em: 27 ago. 2014. 23:55:24.

MOREIRA, J. H. Modelo de gestão para incubação de empresas orientado a capital de risco. 2002. 136 f. Dissertação (Mestrado em Engenharia de Produção). Universidade Federal de Santa Catarina, Florianópolis, 2002.

QUADROS, Felipe Zurita. Plano de negócios e a pequena empresa de base tecnológica: um estudo de caso na incubadora de empresas MIDI Florianópolis. 2004. 133 f. Dissertação (Mestrado em Engenharia de Produção). Universidade Federal de Santa Catarina, Florianópolis, 2004.

RAUPP, F. M.; BEUREN, I. M. Programas oferecidos pelas incubadoras brasileiras às empresas incubadas. RAI - Revista de Administração e Inovação. São Paulo, v. 6, n. 1, p. 83-107, 2009.

SEBRAE. Serviço Brasileiro de Apoio às Micro e Pequenas Empresas. Disponível em: < http://www.sebraesp.com.br/empresas_rede/inovacao_tecnologia/incubadora_empresa > Acesso em: 29 ago. 2014. 13:17:33.

SEBRAE. 10 anos de monitoramento da sobrevivência e mortalidade de empresas. São Paulo: SEBRAE-SP, 2008. 120 p.

SEBRAE-SP. Serviço Brasileiro de Apoio às Micro e Pequenas Empresas de São Paulo. Disponível em: < http://www.sebraesp.com.br/node/8105 > Acesso em: 31 out. 2014. 08:40:50.

UGGIONI, N. Sistema de Acompanhamento e Avaliação de Empresas residentes em Incubadoras. 2002. 108 f. Dissertação (Mestrado em Engenharia de Produção). Universidade Federal de Santa Catarina, Florianópolis, 2002.

VEDOVELLO, C. Aspectos relevantes de parques tecnológicos e incubadoras de empresas. Revista do BNDES, Rio de Janeiro, v. 7, n. 14, p. 273-300, 2000.

VEDOVELlO, C.; PUGA, F. P.; FELIX, M. Criação de infra-estruturas tecnológicas: a experiência brasileira de incubadoras de empresas. Revista do BNDES, Rio de Janeiro, v. 8, n. 16, p. 183-214, 2001.

VERGARA, S. C. Projetos e relatórios de pesquisa em administração. 3.ed. Rio de Janeiro: Atlas, 2000. 